\title{
DO ALL TYPES OF RESTRUCTURING THREATEN EMPLOYEES' WELL-BEING? AN EXPLORATORY STUDY
}

\author{
MARIA WIDERSZAL-BAZYL and ZOFIA MOCKAŁLO \\ Central Institute for Labour Protection - National Research Institute, Warszawa, Poland \\ Department of Ergonomics, Social Psychology Unit
}

\begin{abstract}
Objectives: Most research on the negative impact of restructuring on employees' health considers restructuring involving personnel reduction. The aim of this study was to explore the assumption that the type of restructuring, business expansion versus restructuring not involving expansion (only reductions and/or change of ownership), influences its psychological responses: appraisal of the change, psychosocial working conditions and well-being after the change. Material and Methods: The study was carried out among 857 employees that experienced restructuring in 2009 and/or 2010 and 538 employees from companies not restructured at that time. The main variables, i.e., assessment of change in terms of personal benefits and losses, psychosocial job characteristics and well-being were measured using a questionnaire developed in "The psychological health and well-being in restructuring: key effects and mechanisms" project (PSYRES). Results: It was found that the employees who experienced business expansion in comparison to those who experienced exclusively change of ownership had a higher appraisal of change, while those who experienced restructuring not involving business expansion did not differ from those who experienced change of ownership. As far as psychosocial working conditions are concerned, those employees who experienced exclusively business expansion did not differ from those in the not restructured companies (except for quantitative demands that were higher), while most psychosocial working conditions of the employees who experienced restructuring not involving expansion were poorer than in the not restructured companies. Also, well-being measures of the employees who experienced exclusively business expansion did not differ from those in the not restructured companies (except for innovative behavior that was even higher), while well-being measure of those who experienced restructuring not involving expansion was poorer than of those in the not restructured companies. Conclusions: Restructuring involving exclusively business expansion is not a threat to psychosocial job characteristics (except for quantitative demands) or to employees' well-being. Therefore, the type of restructuring should be taken into account when the restructuring psychological health relationship is discussed.
\end{abstract}

Key words:

Well-being, Restructuring, Change appraisal, Psychosocial job characteristics, Job demands, Innovative behavior

\section{INTRODUCTION}

Much research has shown a negative impact of restructuring on employees' well-being - not just of those who lost their jobs, but also of those who survived the change and remained in the company. These survivors pay substantial costs of the change such as more cardiovascular diseases [1], more musculoskeletal problems [2], worse psychological well-being [3], worse self-rated health [4], sleep problems [5,6], depression [7], increased use of medications [8], increased alcohol consumption [9] and worse functioning at work in terms of professional burnout [10],

This paper was prepared with the frame of the CIOP-PIB's statuatory task No. V-25: Restructuring and employee health: Main effects and psychological mechanisms. Received: February 28, 2014. Accepted: November 12, 2014.

Corresponding author: M. Widerszal-Bazyl, Central Institute for Labour Protection - National Research Institute, Department of Ergonomics, Czerniakowska 16, 00-701 Warszawa, Poland (e-mail: mawid@ciop.pl). 
lack of job satisfaction [11], and increased sickness absence [12,1,13].

The numerous studies that have found negative psychological consequences of restructuring were carried out in conditions of company downsizing. Westgaard and Winkel's [14] review has shown that 26 out of 34 studies of organizations that had experienced downsizing reported negative psychological consequences.

Only recently have the effects of different types of restructuring become the focus of attention, along with the possibility that some types may actually have positive consequences. Westgaard and Winkel [14] have shown that in the case of restructuring involving introduction of high performance work systems (i.e., teams with considerable autonomy, training opportunities and benefits from intensification of work), 6 out of 10 studies reported positive psychological effects of the change, and 2 studies reported partly positive effects.

Loretto et al. [15] have distinguished 5 types of changes experienced by the employees of British restructured health care institutions; they have found that only changes associated with an increased amount of work and job insecurity resulted in deteriorated well-being. However, the opportunity to train and develop led to an opposite effect: improved psychological well-being. Also Cartwright et al. [16], have observed positive effects of restructuring: after 2 British universities merged, psychological and physical well-being of the employees of the newly created organization was better than psychological and physical well-being in the general working population.

This paper is another attempt at tackling the problem of the relationship between different types of restructuring and employees' well-being. Its novelty consists in focusing primarily on business expansion as opposed to other types of restructuring. Previous studies paid little attention to restructuring involving expansion. However, there is a reason to expect that business expansion has different psychological consequences than other types of restructuring, i.e., it results in a different employee's appraisal of the benefits and losses resulting from the change, different perceived psychosocial working conditions and different employee's well-being.

Before formulating the hypotheses, we will discuss the following introductory issues: a) the scale of restructuring involving business expansion in the European Union (EU), b) appraisal of personal benefits and losses caused by restructuring as a determinant of its psychological consequences, c) type of restructuring and psychosocial working conditions and d) previous studies on the consequences of restructuring involving business expansion.

\section{Scale of restructuring involving business expansion in the $\mathrm{EU}$}

Although, as mentioned earlier, studies on the psychological effects of restructuring have focused mainly on personnel reduction, actual restructuring relatively often involves business expansion. Thus, according to the ERM (European Restructuring Monitor [17]), in 2009 and 2010, that is, the period covered by the present study, the EU reported 2832 cases of restructuring, including 614 cases (22\%) classified as business expansion. There has been an even stronger trend towards business expansion in the Central-Eastern Europe, which has undergone a political transformation. The present study took place in Poland, where ERM reported 102 out of 285 cases of restructuring (about 36\%) that involved business expansion.

\section{Appraisal of personal benefits and losses caused by restructuring as a determinant of its psychological consequences}

Early studies on the psychological effects of restructuring have not considered the subjective appraisal of the consequences of restructuring of individuals. Thus, they have disregarded the classic thesis of Lazarus and Folkman [18] that stress reaction or lack of it is a consequence of a subjective appraisal of events. According to Lazarus 
and Folkman [18], we can assume that the consequences of restructuring in terms of well-being depend on how an individual appraises personal benefits and losses caused by the change. When a positive appraisal dominates, better well-being can be expected; whereas when a negative appraisal dominates, worse well-being is more likely.

Several recent studies have reported such outcomes. Cartwright et al. [16] have found that a positive appraisal of personal benefits resulting from a merger was related to better physical well-being, higher commitment to the organization, lower intent to leave and better psychosocial working conditions, especially a greater control.

A Finnish longitudinal study on the merger of 2 companies in the distilling industry has shown that a positive appraisal of personal benefits of a merger led to less stress, emotional exhaustion and cynicism, and greater workability [19]. Moreover, a cross-sectional analysis of a sample of Polish companies that had undergone various types of restructuring has shown that a positive appraisal of benefits of the change was a predictor of better employee's psychological well-being, that is, less stress and emotional exhaustion and more job satisfaction, workability, work engagement, innovativeness and performance [19].

As the way restructuring is appraised is so important for its psychological consequences, it is important to learn how its different types are appraised, i.e., not only those involving personnel reduction, but also those involving business expansion. We have found no study that would answer this question. We can assume that restructuring involving business expansion creates new perspectives not only for the company as a whole, but also for its individual employees. Hence, we expect that restructuring involving business expansion will be appraised better in terms of personal benefits and losses than the other types of restructuring.

\section{Restructuring and psychosocial working conditions}

Psychosocial working conditions are important mediators in the relationship between restructuring and an employee's well-being. Restructuring increases job demands [20,21], job insecurity [20,22,2] and work-family conflict [19]; it decreases task clarity [19] and thus, worsens an employee's well-being.

However, it is not restructuring itself, but rather the personal appraisal of benefits and losses associated with it that has an impact on the perceived job characteristics after the change. The higher the appraisal of personal benefits compared to losses, the higher the appraisal of psychosocial working conditions after the change, that is, working conditions with more control, more social support, more role clarity and more participation in decision-making [23].

As we expect the type of restructuring (i.e., expansion vs. other types) to have impact on an employee's appraisal of personal benefits and losses, consequently, we should expect the type of restructuring to influence the perceived working conditions. Restructuring involving business expansion should be conducive to better psychosocial working conditions compared to the other types of restructuring.

\section{Type of restructuring and employees' well-being}

As mentioned earlier, studies on restructuring involving downsizing have quite clearly demonstrated its negative effects on an employee's well-being. However, there have been few studies on the psychological effects of restructuring involving business expansion. Moreover, their results are ambiguous.

In their epidemiological studies on the working population of Stockholm, Sweden, Theorell et al. [24] considered companies that had experienced increased employment (over 8\%). They have found that during the 12-month period following the change in the number of staff, there were fewer medically certified sick leaves than in the stable companies. This result could be considered as an indicator of better employees' health after expansion. On the other hand, it can also indicate that 
employees were so anxious about their jobs that they were afraid to take sick days. The authors are inclined to the latter interpretation, they believe that the phenomenon of presenteeism has taken place, i.e., employees attended work despite being ill. However, it should be noted that it is hard to decide how it really was because the number of sick leaves is not an unequivocal marker of well-being - it can reflect high as well as low well-being. Additionally, in the Theorell et al.'s study [24] there were no direct measures of well-being.

Other Swedish researchers, Westerlund et al. [25], studied a large national sample and they have obtained different results than the ones described above: they have found that in the companies with increased employment, longterm absenteeism (over 90 days) was increased. However, also in this study subjective aspects of well-being have not been taken into account, so it is not clear what psychological effects were related to this outcome.

It thus follows, that there have been no studies on the impact of restructuring involving business expansion - as opposed to the other types of restructuring - on psychological well-being. As we expect restructuring involving expansion to have higher employees' appraisal in terms of personal benefits and, at the same time, there is empirical evidence of the relationship between appraisal of restructuring and employees' well-being, we assume that restructuring involving expansion is related to better employees' well-being than in the case of the other types of restructuring.

\section{AIM AND HYPOTHESES}

The aim of this study was to investigate whether the type of restructuring - business expansion as opposed to the other types of restructuring, is significantly related to: a) subjective appraisal of restructuring in terms of personal benefits and losses, b) perceived psychosocial working conditions after the change, and c) employees' well-being after the change.
The following hypotheses were tested:

1. Restructuring involving business expansion is appraised better in terms of personal benefits and losses than restructuring not involving expansion.

2. Restructuring involving business expansion is related to less stressful psychosocial working conditions than restructuring not involving expansion.

3. Employees' well-being after restructuring involving business expansion is better than in the case of restructuring not involving expansion.

\section{MATERIAL AND METHODS}

\section{Participants and procedure}

The study took place in 2011. Selection of participants was performed in 2 stages:

1. Two types of companies were selected: restructured in 2009, 2010, or both, and not restructured at that time. ERM's database [17] was the starting point for selecting the restructured sample. According to the ERM [17], in Poland, 186 companies were restructured in 2009 and 57 companies in 2010. Because it was not possible to make an appointment in many of these companies within the period available for the research project, the Kompass database [26] was also used to identify the restructured companies. There is no information on restructuring in that database so, to assign a company either to the restructured or non-restructured sample, representatives of the companies' management were contacted by phone.

2. Employees were randomly selected from each restructured and nonrestructured company. The following principles were adopted: a) no more than 10 and 20 respondents were selected from the companies with under and over 100 employees, respectively; b) in the companies with over 500 employees, the respondents were selected only from the departments that had been restructured; c) to participate, the respondents had to have worked in the company for at least 2 years prior to the study. 
In total, 1396 employees from 96 organizations from different economic sectors took part in the study. The sample of employees from the restructured companies consisted of 857 employees from 57 companies. The control group consisted of 538 employees from 39 not restructured companies.

Approximately 53\% of the respondents were women. All age groups were represented, with most employees aged 31-40 (27\% of all the respondents). The youngest group consisted of people under 30 (17\%), the oldest respondents were over 60 (2\%). Fifty-eight percent had completed tertiary education, $35 \%$ had completed secondary education. Seventy-four percent had a permanent contract, and $20 \%$ held supervisory positions.

\section{Measures}

The restructuring questionnaire developed within the PSYRES ("Psychological health and well-being in restructuring: Key effects and mechanisms") project [19] was the main measure; its scales measure all the variables in the hypotheses.

\section{Type of restructuring}

Two blocks of multiple-choice questions determined the type of restructuring. A general question preceded the first block: "Have some of the following changes of the ownership taken place in your workplace during the past 2 years?". The block itself consisted of five items on the following changes: a) privatization, b) company sold to another owner, c) company taken over by another company, d) company took over another company, e) merger.

The second block of items was preceded with a similar general question on changes other than ownership-related. It consisted of five items on a) outsourcing, b) personnel reduction, c) investment for increased production, d) investment for expansion into new lines of business, e) other significant changes. In each case, there were 4 options: no; yes, in 2009; yes, in 2010; I don't know. The responses led to the following empirical classification of restructuring types:

1. Expansion: a company experiences expansion related to the investment for increased production, investment for new lines of business, or both.

2. Expansion + change of ownership: a company experiences expansion (in terms of type 1) and the change of ownership.

3. Expansion + reduction: a company experiences expansion (in terms of type 1) and reduction (in terms of type 5).

4. Expansion + reduction + change of ownership: a company experiences expansion (in terms of type 1), reduction (in terms of type 5), and change of ownership.

5. Reduction: a company experiences personnel reduction, outsourcing, or both. Those changes were considered together because we believe outsourcing is a form of reduction. Outsourcing always results in elimination of certain types of activities performed inside a company, even if it there is no personnel reduction.

6 . Reduction + change of ownership: a company experiences reduction (in terms of type 5) and change of ownership.

7. Change of ownership: a company experiences change of ownership only, with neither reduction nor expansion.

As it can be seen above, the first empirically differentiated type of restructuring refers exclusively to business expansion, the next 3 types (2, 3 and 4 ) - to business expansion mixed with other types, and the remaining 3 types - to the restructuring not involving expansion.

\section{Restructuring appraisal}

Appraisal of restructuring was measured with a 10 -item scale preceded with a general question on what had changed due to restructuring. The items focused on changes in a) tasks at work, b) superior, c) team, d) amount of work, e) influence within organization, f) risk of job loss, 
g) recognition, h) career prospects, i) conditions of employment, j) salary, fringe benefits, or both.

The respondents answered on a 6-point scale where $0=$ no change, 1 = got significantly worse, 5 = got significantly better. Cronbach's $\alpha$ for this scale was 0.91 . The scale as a whole was original, but ideas for some questions came from the HYVIS survey [27] and the Change Impact Factor scale [28]. The response format was similar to that in the Oreg's Perceived Outcomes of the Change scale [29].

\section{Psychosocial working conditions}

The 3 basic dimensions of the demand-control-support model [30], that is, quantitative demands, control and support were measured with the Copenhagen Psychosocial Questionnaire (COPSOQ [31]) in its Polish version [32].

Other psychosocial characteristics were also measured. Effort-reward imbalance was measured with a short version of the Effort-Reward Imbalance (ERI) questionnaire [33], which was limited to 3 items that directly measured the effort-reward imbalance. Job insecurity was assessed with 2 , slightly modified, questions derived from the Cohort Study of Social Innovation (CSI) questionnaire [34]. Task clarity was measured with 2 scales from the medium version of the COPSOQ: role clarity and role conflict [31]. Work-family conflict was assessed with 2 questions derived from the CSI questionnaire [34].

\section{Employees' well-being}

Both negative and positive aspects of well-being were measured. Work-related stress was assessed with a question from the Occupational Stress Questionnaire by Elo et al. [35]. The question was as follows: "Stress means the situation when a person feels tense, restless, nervous, or anxious, or is unable to sleep at night because his or her mind is troubled all the time. Do you feel that kind of work-related stress these days?". The response scale ranged from 1 (not at all) to 5 (very much).

Emotional exhaustion was measured with a 5-item scale derived from the UBOS burnout scale [36]. The shortened form of the UBOS was used successfully in the Netherlands Working Conditions Survey [37]. The Cronbach's $\alpha$ of the Polish short form used in the present study was 0.83 . Intent to leave was measured with a question agreed by the PSYRES group for the purpose of this study: "Are you planning to be in your current workplace in five years?". The response scale ranged from 1 (yes, absolutely) to 5 (absolutely not). Sickness absence was assessed with a question on the number of sick days taken in the past year.

Work engagement was measured with 3 questions from the short version of the Utrecht Work Engagement Scale (UWES-9 [38]). Polish version of UWES has been already used in the study of 993 Polish workers in various occupations [39]. The 3 questions used in the present study where those that, according to Kauppinen et al. [40], correlated best with the whole scale. The Cronbach's $\alpha$ of the Polish version of this 3-item scale was 0.85 .

Job satisfaction was assessed with a question used in the "Still Working" study [41]: "How satisfied are you with your present work?" with a 5-point response scale, from "very dissatisfied" to "very satisfied".

Work ability was measured with 4-items from the Work Ability Index by Tuomi, Ilmarinen, Jahkola, Katajarinne, and Tulkki [42], in the Polish adaptation by Pokorski [43]. Innovative behavior was assessed with a 4-item scale from the Netherlands Working Conditions Survey [37]. Question 1 polled the extent to which employees were encouraged to reflect on improving their working methods. It was derived from the QPS Nordic questionnaire [44]. Question 2 polled the amount of time for creating new ideas. Questions 3 and 4 measured exploratory innovation (creating new solutions) and operational innovation (improvements of existing 
solutions), respectively, to use Jansen, van den Bosh, and Volberda's [45] nomenclature. The respondents answered these questions on a 5-point Likert scale, where $1=$ never and $5=$ always.

Performance was assessed with a question formulated by the PSYRES group for the purpose of this study. To avoid self-evaluation of performance in comparison to other employees (which could be affected by the social approval factor), the respondents compared their current performance, performance with that from 1 or 2 years earlier. The respondents answered this question on a 5 -point Likert scale, where $1=$ much worse and $5=$ much better.

\section{Data analysis}

Three series of regression analyses were carried out. The 1st one aimed at testing hypothesis 1 and included one analysis with the appraisal index as a dependent variable.

The 2nd series aimed at testing hypothesis 2 and included 7 regression analyses with psychosocial working conditions as dependent variables. Depending on the analysis, these were: quantitative demands, control, social support, task clarity, job insecurity, work-family conflict and effortreward balance.

Finally, the 3rd series of regression analyses consisted of 9 analyses with well-being indicators as dependent variables, i.e., respectively: stress, exhaustion, job satisfaction, engagement, work ability, innovative behavior, performance, sickness absence, intent to leave.

Types of restructuring were predictors in all of the above mentioned analyses. Because these were qualitative predictors, they had to be encoded in order to be incorporated into regression analyses.

In regression analysis with quantitative categories, each category is compared separately with a reference group. Standarized $\beta$ coefficient describes the direction and the significance of the difference between the 2 means: a reference group and a given category means [46].
The group that did not experience restructuring was the reference group in the case of the 2 nd and 3 rd series of regression analyses, with psychosocial working conditions and well-being indicators, respectively. In other words, in those analyses, the group that did not experience restructuring has been compared with groups experiencing a given type of restructuring, that is, type 1 (expansion), type 2 (expansion + change of ownership), type 3 (expansion + reduction), type 4 (expansion + reduction + change of ownership), type 5 (reduction) and type 6 (reduction + change of ownership).

However, in the 1st series of regression analyses, it was not possible to use the same reference group because the group that did not experience restructuring - for obvious reasons - did not fill out that part of the questionnaire that referred to restructuring appraisal. So in this case, the group that experienced the change of ownership only, with neither reduction nor expansion, was the reference group. It was assumed that the change of ownership is indifferent as far as a reduction-expansion dimension is concerned. So it was a convenient frame of reference for testing hypothesis 1.

Because the original change appraisal index had negative values, too (from -20 to +20 ), it was recoded into a positive-only index (from 1 to 40 ).

\section{RESULTS}

\section{Type of restructuring and its appraisal}

Results of the regression analysis with restructuring appraisal in terms of personal benefits and losses as a dependent variable indicated that a type of restructuring was related to its appraisal (Table 1). It explained $9 \%$ of variance of the appraisal (together with age that was negatively related to the appraisal). Among the 7 types of restructuring taken into account, business expansion had the highest regression coefficient that means it differed to the highest degree from the reference group, i.e., from the employees who experienced the change of ownership only. 
Table 1. Multiplicative regression analysis of the relationships between the types of restructuring and their appraisals

\begin{tabular}{lc}
\hline \multicolumn{1}{c}{ Independent variable } & $\beta$ coefficients \\
\hline $\begin{array}{l}\text { Type of restructuring } \\
\text { business expansion only }\end{array}$ & \\
$\quad$ 1. expansion $(\mathrm{N}=147)$ & $0.23^{* * *}$ \\
business expansion and other changes & 0.07 \\
2. expansion + change of ownership $(\mathrm{N}=77)$ & $0.15^{*}$ \\
3. expansion + reduction $(\mathrm{N}=220)$ & $0.12^{*}$ \\
4. expansion + reduction + change of ownership $(\mathrm{N}=92)$ & \\
no business expansion & -0.06 \\
5. reduction $(\mathrm{N}=170)$ & -0.04 \\
$\quad$ 6. reduction + change of ownership $(\mathrm{N}=64)$ & \\
Control variable & -0.00 \\
gender & $-0.14^{* * *}$ \\
age & -0.03 \\
education & 0.09 \\
$R^{2}$ & \\
\hline
\end{tabular}

${ }^{1}$ The group that experienced change of ownership only, with neither reduction nor expansion $(\mathrm{N}=60)$ was the reference group in the regression model. * $\mathrm{p}<0.05 ; * \mathrm{*}<0.01 ; * * \mathrm{p}<0.001$.

$R^{2}$ - the percent of the dependent variable explained by the model; $\beta$-standardized regression coefficient.

In other words, appraisal of benefits in relation to losses caused by restructuring involving business expansion, was significantly higher than the analogical appraisal of restructuring involving the change of ownership only.

Two other types of restructuring involving business expansion in which expansion was mixed with other changes (reductions or reductions plus ownership changes group 3 and 4, respectively) were also appraised higher than the reference group. However, in this case, regression coefficients were a bit lower $(\mathrm{p}<0.05)$ than in the group with pure business expansion $(\mathrm{p}<0.001)$. The remaining group involving expansion, in which expansion was mixed with the change of ownership (the group 2), did not differ significantly from the reference group.

The two types of restructuring not involving business expansion (exclusively reductions or reductions plus the change in ownership - group 5 and 6, respectively) did not differ significantly in their appraisals from the reference group. In other words, appraisal of benefits and losses were similar in the case of restructuring involving exclusively changes of ownership and in the case of other types of restructuring not involving business expansion.

Summing up, restructuring involving pure business expansion had the highest appraisals, the 2nd place - as far as appraisals of personal benefits and losses are concerned - belonged to the restructuring involving expansion mixed with other changes such as reductions or ownership changes (out of the 3 types of restructuring of that kind, in 2 types appraisals were higher than in the reference group). Restructuring types not involving business expansion, i.e., exclusively reductions, exclusively changes of ownership or reductions mixed with changes of ownership, had the lowest appraisal of personal benefits in relation to losses. 


\section{Type of restructuring}

\section{and psychosocial working conditions}

Results of regression analyses with 7 psychosocial working conditions as dependent variables revealed that all types of restructuring were associated with higher quantitative demands in comparison to the reference group, i.e., the group of employees who did not experience restructuring. The remaining psychosocial working conditions were variously associated with restructuring depending on its type.

Restructuring involving pure business expansion (group 1) was significantly related to the above mentioned quantitative job demand only. Relationships between expansion and all the remaining job characteristics turned out to be insignificant.

The three types of restructuring involving business expansion mixed with other changes (groups: 2, 3 and 4) were significantly related to 2 to 5 job characteristics. So, in the case of restructuring involving expansion mixed with ownership changes (group 2) differences in relation to the reference group were: higher job demands and lower effort-reward balance. And in the case of business expansion mixed with reductions (group 3), differences were additionally: lower task clarity, higher job insecurity and higher work-family conflict.

A similar situation was in the case of restructuring involving expansion mixed with reductions and ownership changes (group 4) - differences were the same as in group 3 described above except for effort-reward balance that was insignificant.

The 3 types of restructuring not involving business expansion differed from the reference group to the highest extent. It especially applied to pure reductions (group 5 - Table 2) where all 7 job characteristics included in the study were poorer than in the reference group: higher demands, lower control, lower social support, lower task clarity, higher job insecurity, higher work-family conflict and poorer effort-reward balance.
Summing up, it can be said that all the types of restructuring have been associated with poorer psychosocial working conditions in comparison to the not restructured companies. However, in the case of pure business expansion it concerned only 1 job characteristic. In the case of business expansion mixed with other changes, it concerned from 2 to 5 job characteristics that means 3.7 on average. And in the case of restructuring not involving expansion - from 5 to 7 job characteristics that means 6 on average.

\section{Type of restructuring and employees' well-being}

Regressions with well-being measures as dependent variables revealed that in the case of pure business expansion, 1 measure - innovative behavior - had more desirable level than in the reference group (group 1 - Table 3). All the remaining well-being measures did not differentiate expansion from the reference group.

In the case of business expansion mixed with other changes (groups 2, 3 and 4 - Table 3) either no differences in well-being measures in comparison to the reference group were found (it concerns group 2) or only few differences in the positive as well as in the negative direction. So, in the case of expansion mixed with reductions (group 3) these negative differences referred to higher stress and exhaustion, lower work ability. However, 1 positive difference was also revealed: higher innovative behavior. Then, in the case of business expansion mixed with reductions and changes of ownership (group 4), 1 difference in the negative direction was revealed - higher stress, and 1 difference in the positive direction - higher performance.

In the case of restructuring not involving business expansion (groups 5, 6 and 7 - Table 3) poorer well-being measures were found in comparison to the reference group. It referred to majority of the well-being measures taken into account except for sickness absence that was an insignificant variable in all the restructuring groups. So, in the 


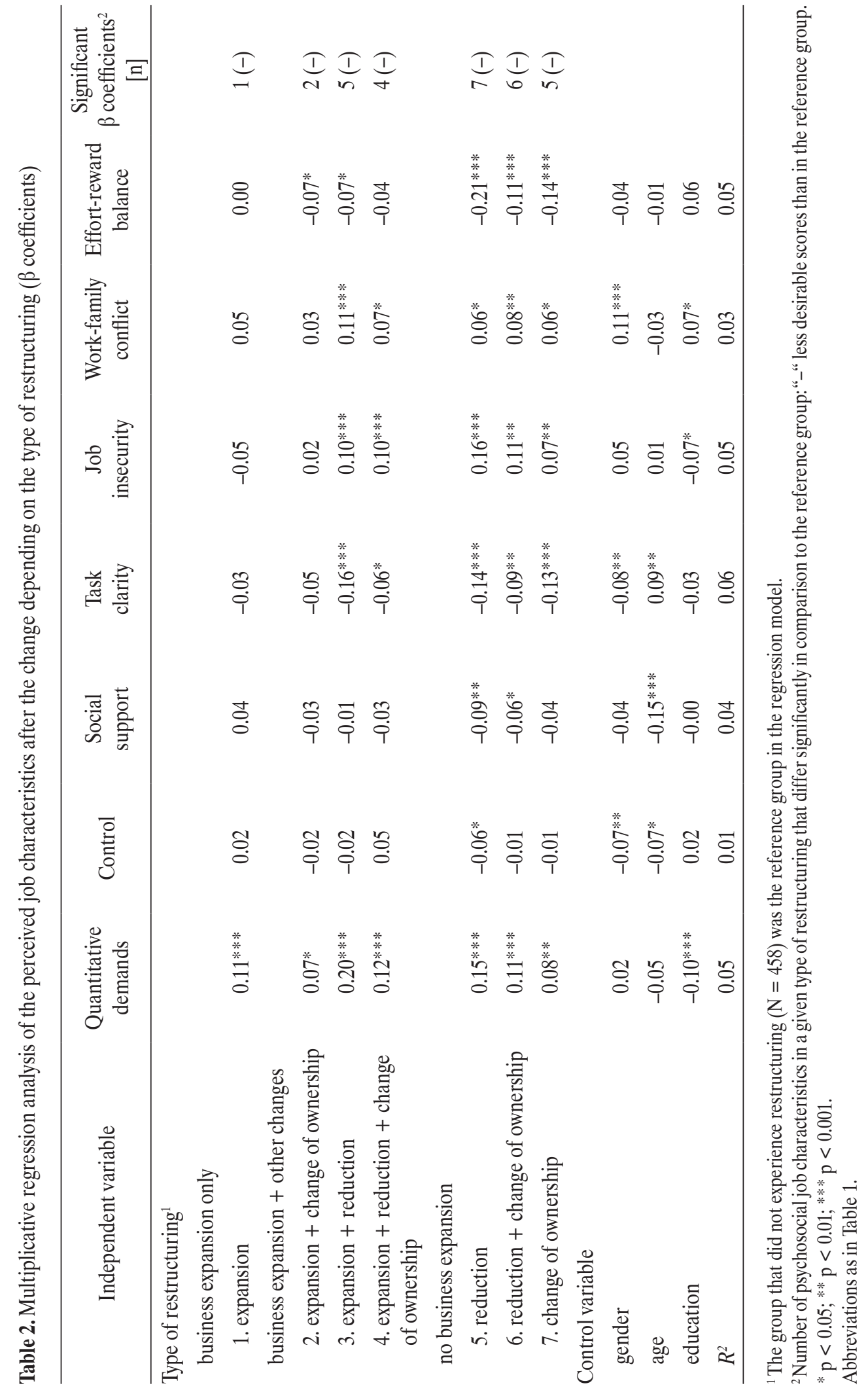




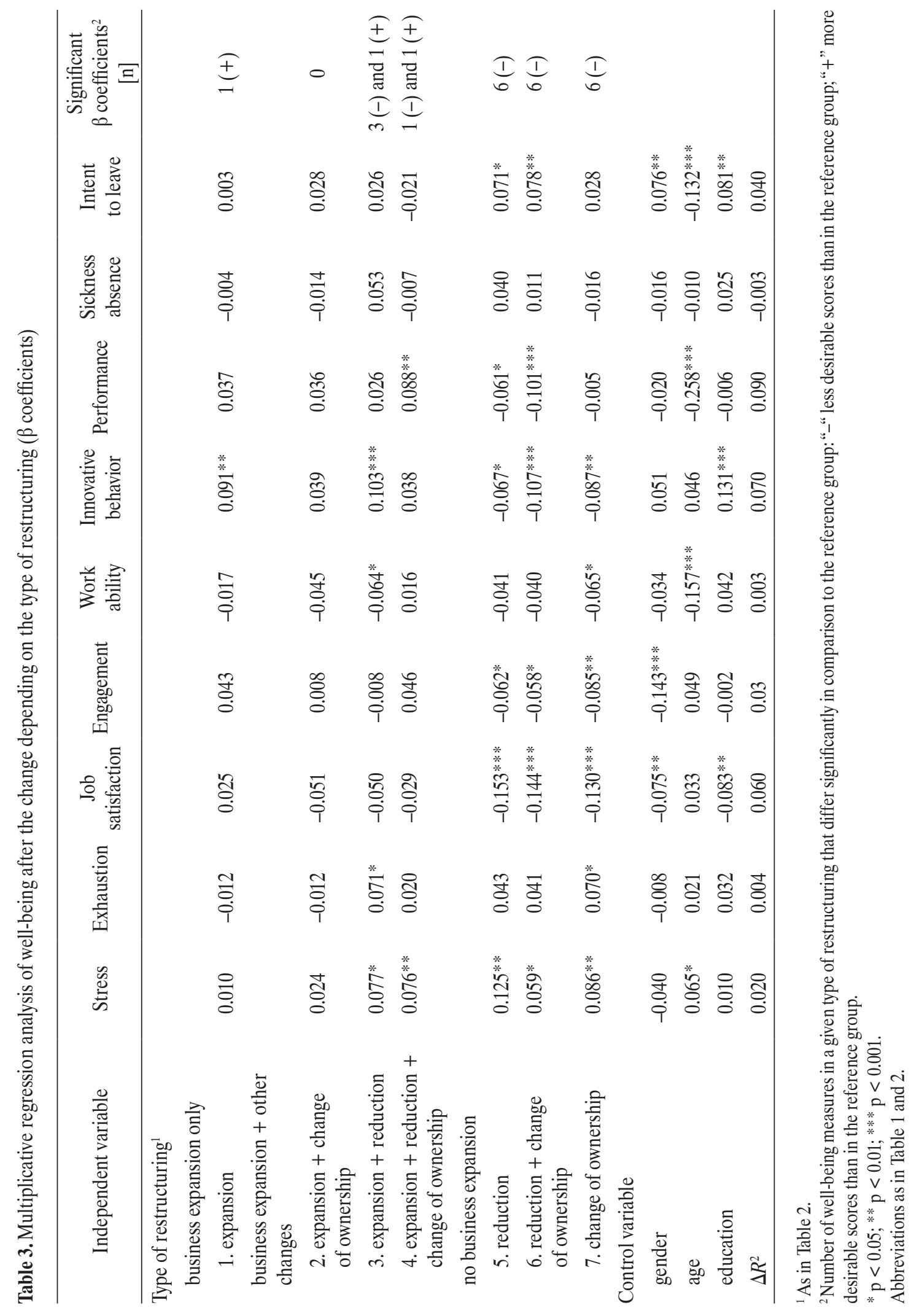


case of pure changes of ownership (group 7), higher levels of stress and emotional exhaustion, also lower levels of job satisfaction, engagement, work ability and innovative behavior were revealed. Similarly, in the case of pure reductions (group 5) the negative differences referred to higher stress and intention to leave, also to lower: job satisfaction, engagement, innovative behavior and performance.

Summing up the results concerning well-being, it should be said that only restructuring involving pure business expansion was related exclusively to a positive indicator of well-being, namely a higher level of innovative behavior. And it was not related to any negative indicator of well-being. In turn, business expansion mixed with other changes was related to both, some undesirable well-being indicators (1-3 indicators in the negative direction) and some desirable ones (the latter concerned innovative behavior or performance level). On the other hand, the types of restructuring not involving business expansion were related exclusively to the undisareble well-being measures in comparison to the reference group (each type of this kind related to 6 negative indicators)

\section{DISCUSSION AND CONCLUSIONS}

The study made it possible to compare reactions of the employees that experienced various types of restructuring with special attention to a differentiation between restructuring involving business expansion vs. restructuring not involving expansion (but only reduction and/or change of ownership). Thanks to such an attitude it made it possible to verify the thesis that a type of restructuring is a factor influencing its psychological consequences. This kind of analysis seemed to be especially important in the current situation when the vast majority of published psychological research has been focused on restructuring involving personnel reduction. As a consequence, reports on destructive effects of restructuring on an employee's health dominated [e.g., 8,47].

Hypotheses of this study were based on the assumption that restructuring involving business expansion should be differentiated from the other types of restructuring because business expansion widens a company's scope of activities, thereby, it also creates better opportunities for action and personal development for an individual employee. The results have confirmed the hypotheses.

Following hypothesis 1 , it was revealed that indeed restructuring involving business expansion is associated with a higher assessment of benefits in relation to losses in comparison to restructuring involving ownership change only. The latter did differ from restructuring involving exclusively personnel or/and activity reduction in this respect. High assessment of benefits in relation to losses were especially clear in the case of pure business expansion. It is interesting that also in the cases when business expansion was mixed with reductions and additionally with changes of ownership - a profit and loss account was more desirable for an employee than in the case of changes of ownership only, without business expansion. It might prove that only certain elements of business expansion - even when it is mixed with other changes - create a situation that is positively assessed by an employee.

Following hypothesis 2, psychosocial working conditions after restructuring involving business expansion were better than after restructuring not involving expansion. Such a conclusion is justified by the result indicating that psychosocial job characteristics after business expansion were the same as in the not restructured companies, except for one only. However, in a group of employees who experienced only reductions and/or changes of ownership, 5 to 7 job characteristics were less desirable than in the not restructured companies. It referred to higher quantitative job demands, job insecurity, work-family conflict and lower: task clarity, effort-reward balance, and sometimes also lower social support and control.

The results related to business reduction are in line with the previous studies, which have shown the impact of reduction on such psychosocial working conditions 
as: job insecurity, and demands [20,22,4]. However, so far there have been no studies on the impact of expansion on psychosocial working conditions. The results of this study showed that generally, working conditions after business expansion were not poorer than in the not restructured companies. Quantitative demands were the only exception: the employees who experienced business expansion perceive them as higher than the employees who did not experience restructuring. So, even the employees after restructuring involving expansion pay certain costs of change, mainly in terms of higher work quantity. However, these costs are lower than in the case of the other types of restructuring. It is likely that these additional costs are an effect of the change itself, even of the change that is highly appraised and which in the long term probably leads to more satisfying working conditions.

Hypothesis 3, assuming that employees' well-being after restructuring involving business expansion is higher than after restructuring not involving it, has also been confirmed. The results indicating that there were no significant differences in well-being measures between the employees who experienced exclusively business expansion and those with no restructuring at all, with only 1 exception concerning innovative behavior (higher in business expansion group) prove it. On the other hand, in the group that experienced restructuring not involving business expansion, 6 well-being measures were less desirable than in the reference group, i.e., not involving restructuring.

Those employees reported higher stress and lower: engagement, job satisfaction, innovative behavior, and sometimes also - depending on a particular group - higher exhaustion and intent to leave and lower work ability and performance. These results are in accordance with other reports on poor well-being of the employees after restructuring involving ownership changes or/and personnel reductions. However, this research provides supplementary evidence that poor well-being does not refer to the employees who experienced exclusively business expansion. Innovative behavior is worth special attention as it is the only well-being indicator that showed a more desirable level after business expansion than in the case of the not restructured group. Existing literature explains a number of circumstances that foster workplace innovation, e.g., job complexity, role expectations regarding creativity and innovation, employees' autonomy, positive work climate, supervisory support, transformational leadership, or organizational resources [48]. The present study suggests that undertaking changes aiming at growth or expansion of the current scope of activity may play a role in enhancing employees' innovative behavior.

We can wonder why innovative behavior turned to be the only indicator demonstrating better well-being of the employees who experienced business expansion, while all the other well-being indicators did not differentiate these employees from the reference group. It is likely that the reasons of that are similar to those mentioned in the context of psychosocial job characteristics.

One reason is the high cost of adaptation to change even if this change is positively appraised. Adaptation to change always requires the effort to learn the new and to adopt to the new conditions. In other words, it requires additional psychological costs that can decrease subjective well-being in the short run.

The 2 nd reason could be the short time between the restructuring and measuring the employees' responses. It is likely that in the long term the employees would adapt to the new situation better, they would appreciate the positive aspects of expansion and the impact on their wellbeing would be clearer.

Macro trends in working conditions and employees' wellbeing in societies where restructuring of companies, especially expansion, constitute intensive support for this interpretation. Poland is one of these societies. According to the European Restructuring Monitor from 2004, 
May 1 until now, there were 1741 restructuring cases in Poland including numerous cases of expansion: 1216 (70\%). Also, the results of the subsequent European Working Condition Surveys [12] have shown that a number of psychosocial working conditions were perceived better. The good example is the 2010 survey which has shown that the perceived employees' control over their own job was higher than in the 2005 survey: more respondents claimed that they had control over choosing working methods (change from $62.6 \%$ to $66 \%$ ) and control over task order (change from $62.4 \%$ to $64.6 \%$ ). Also, employees' wellbeing had improved in many dimensions. Satisfaction with the working conditions increased $(15.6 \%$ very satisfied in $2005,19.5 \%$ in 2010) as well as the sense of a job well done $(83.2 \%$ and $85 \%$ always or usually satisfied, respectively). Therefore, it is possible that positive consequences of expansion are more apparent in the long term.

\section{LIMITATIONS AND STRENGTHS}

The limitation of the present study consists in its crosssectional design. Restructuring appraisal as well as perception of psychosocial working conditions and wellbeing were assessed at a single point after restructuring. We had no measures before restructuring and longer time after it. No assessment before restructuring made it impossible to learn what changes in the analysed parameters took place in individual groups. Thus, it is not clear whether differences in the employees' reactions were really the effect of a given type of restructuring or other uncontrolled factors. On the other hand, no assessment longer time after restructuring made it impossible to find out to what extent the responses were temporary or stable, and if they evolved over time, in what direction they evolved. Have the differences between groups decreased over time or have they increased? The present study does not allow us to answer this important question. Another limitation of the study is the fact that the data on the types of restructuring came from self-reports. Hence, they were not objective. Therefore, it cannot be ruled out that at least some respondents could have been affected by other types of restructuring which they were aware of. This weakness can paradoxically be also the strength of the study, because it means that only those cases of restructuring were considered that the respondents noticed (and felt). An objective change introduced by top management, especially in large organizations, does not always reach the bottom of the organization and it does not always change working conditions. This is why it is difficult to expect psychological effects of such changes. If we are interested in psychological effects, it is better to focus on the noticed and felt changes.

The strength of the study consists in the fact that it considers a wide range of restructured organizations, distinguished on that basis business expansion and others types of restructuring, and compares those types with the same set of instruments. This made it possible to go beyond the frequently asked question whether restructuring is associated with negative psychological effects, and to focus on a more specific question - what types of restructuring are or are not associated with negative psychological effects.

\section{PRACTICAL IMPLICATIONS}

In practice, it is important that this study confirmed previous results that restructuring involving change of ownership and business reduction was related to significantly worse psychosocial working conditions and employees' well-being. Hence, such cases of restructuring require careful psychosocial risk management during the change. It puts additional responsibilities on managerial staff, HR and OSH specialists, as well as on the organizations' medical services. They should - each within their scope - conduct a systematic assessment of psychosocial risk, especially during periods of restructuring involving reductions and change of ownership, and an assessment of health effects of the changes. They should 
also undertake activities reducing the negative impact of these types of restructuring on working conditions and employees' well-being.

Good practices in this area [19] show that these activities should focus on ensuring good communication within the organization (bottom - top), employees' participation in the change process, and different forms of social (e.g., additional employees' meetings) and organizational support (e.g., vocational training adjusting skills to the change). Medical services play an important role not only through participation in a psychosocial risk assessment (assessing its health aspects), but also through providing preventive measures, such as staff stress management trainings, promoting a healthy lifestyle and physical activity, or counseling mental health problems that may develop in the period of restructuring [49,50].

Another important outcome of this study is that restructuring involving business expansion only is not a threat to psychosocial working conditions or well-being (in comparison to the not restructured companies) with the exception of quantitative work demands. Therefore, reducing an excessive increase in the amount of work is an important recommendation that managers responsible for this type of restructuring should consider. Last but not least: business expansion can act as a stimulus for employees' innovative behavior.

Because business expansion is associated with the increased workload too, social partners (i.e., managers, HR professionals, occupational safety and health (OSH) services) should be aware of this hazard, and carry out psychosocial risk assessment before, during and after the change. They should also undertake corrective and preventive actions mentioned above in the context of toxic forms of restructuring. However, especially in the case of business expansion, these measures should be accompanied by a clear message to the employees about new chances and opportunities that they face. It may facilitate their acceptance and faster adaptation to the change.

\section{REFERENCES}

1. Vahtera J, Kivimäki M, Pentti J, Linna A, Virtanen M, Virtanen P., et al. Organisational downsizing, sickness absence, and mortality: 10-town prospective cohort study. Br Med J. 2004;328(7439):555-8, http://dx.doi.org/10.1136/ bmj.37972.496262.0d.

2. Kivimäki M, Vahtera J, Ferrie J, Pentti J. Organizational downsizing and musculoskeletal problems in employees: A prospective study. J Occup Environ Med. 2001;58(12): 811-7, http://dx.doi.org/10.1136/oem.58.12.811.

3. Kivimäki M, Vahtera J, Elovainio M, Penti J, Virtanen M. Human costs of organizational downsizing. Comparing health trends between leavers and stayers. Am J Community Psychol. 2003;32:57-67.

4. Kivimäki M, Vahtera J, Pentti J, Thomson L, Griffiths A, Cox T. Downsizing, changes in work, and self-rated health of employees: A 7-year 3-wave panel study. Anxiety Stress Coping. 2001;14:59-73, http://dx.doi.org/10.1080/10615800108248348.

5. Greubel J, Kecklund G. The impact of organizational changes on work stress, sleep, recovery and health. Ind Health. 2011;49(3):353-64, http://dx.doi.org/10.2486/indhealth.ms1211.

6. Campbell-Jamison F, Worral L, Cooper C. Downsizing in Britain and its effects on survivors and their organizations. Anxiety Stress Coping. 2001;14:35-58, http://dx.doi. org/10.1080/10615800108248347.

7. Moore S, Grunberg L, Greenberg E. Repeated downsizing contact: The effects of similar and dissimilar layoff experiences on work and well-being outcomes. J Occup Health Psychol. 2004;9(3):247-57, http://dx.doi.org/10.1037/1076-8998.9.3.247.

8. Kivimäki M, Honkonen T, Wahlbeck K, Elovainio M, Pentti J, Klaukka T, et al. Organizational downsizing and increased use of psychotropic drugs among employees who remain in employment. J Community Environ Health. 2007;61:154-8, http://dx.doi.org/10.1136/jech.2006.050955.

9. Frone MR. Are work stressors related to employee substance use? The importance of temporal context assessments of alcohol and illicit drug use. J Appl Psychol. 2008;93(1):199-206, http://dx.doi.org/10.1037/0021-9010.93.1.199. 
10. Aiken LH, Clarke SP, Sloane DM, Sochalski J, Silber H. Hospital nurse staffing and patient mortality, nurse burnout, and job dissatisfaction. JAMA. 2002;288:1987-93, http://dx. doi.org/10.1001/jama.288.16.1987.

11. Armstrong-Stassen M, Cameron SJ. Nurses' job satisfaction and turnover intentions over 6-year period of hospital downsizing and amalgamation. Int $\mathrm{J}$ Public Adm. 2003;26(14):1607-20, http://dx.doi.org/10.1081/pad120024413.

12. Bourbonnais R, Brisson C, Vézina M, Masse B, Blanchette C. [Psychosocial work environment and certified sick leave among nurses during organizational changes and downsizing]. Relations Industrielles. 2005;60(3):483-509, http://dx.doi.org/10.7202/012156ar. French.

13. Kivimäki M, Vahtera J, Pentti J, Ferrie JE. Factors underlying the effect of organisational downsizing on health of employees: Longitudinal cohort study. Br Med J. 2000; 320:971-5, http://dx.doi.org/10.1136/bmj.320.7240.971.

14. Westgaard RH, Winkel J. Occupational musculoskeletal and mental health: Significance of rationalization and opportunities to create sustainable production systems - A systematic review. Appl Ergon. 2011;42(2):261-96, http://dx.doi. org/10.1016/j.apergo.2010.07.002.

15. Loretto W, Platt S, Popham F. Workplace change and employee mental health: Results from a longitudinal study. Br J Manage. 2010;21(2):526-40, http://dx.doi.org/10.1111/ j.1467-8551.2009.00658.x.

16. Cartwright S, Tytherleigh M, Robertson S. Are mergers always stressful? Some evidence from higher education sector. Eur J Work Organ Psychol.2007;16(4):456-78, http:// dx.doi.org/10.1080/13594320701606391.

17. Eurofound. Fifth European Working Conditions Survey, Publications Office of the European Union. Luxembourg: European Restructuring Monitor; 2012 [cited 2014 Feb 20]. Available from: http://www.eurofound.europa.eu/emcc/erm/ index.htm.

18. Lazarus R, Folkman S. Stress, appraisal, and coping. New York: Springer; 1984.
19. Wiezer N, Nielsen K, Pahkin K, Widerszal-Bazyl M, de Jong T, Mattila-Holappa $\mathrm{P}$, et al. Exploring the link between restructuring and employee well-being. Warszawa: Central Institute for Labour Protection - National Research Institute [cited 2014 Feb 20]. Available from: http://www. ciop.pl/CIOPPortalWAR/file/47257/PSYRES_book.pdf.

20. Geuskens GA, Koppes LLJ, van den Bossche SNJ, Joling CI. Enterprise restructuring and the health of employees: A cohort study. J Occup Environ Med. 2012;54:4-9, http://dx. doi.org/10.1097/jom.0b013e31823c766e.

21. Brown C, Arnetz B, Petersson O. Downsizing within a hospital: Cutting care or just cost? Soc Sci Med. 2003;57: 1539-46, http://dx.doi.org/10.1016/s0277-9536(02)00556-7.

22. Armstrong-Stassen M. Designated redundant but escaping lay-off: A special group of lay-off survivors. J Occup Organ Psychol. 2002;75:1-13, http://dx.doi.org/10.1348/096 317902167603.

23. Widerszal-Bazyl M, Mockałł Z. Restructuring, its appraisal and employees well-being: Piloting the new restructuring questionnaire. The 9th International Conference on Occupational Stress and Health 2011: Work and well-being in an economic context; 2011 May 19-22; Orlando, Florida, USA [cited 2014 Feb 20]. Available from: http://www.ciop. pl/CIOPPortalWAR/file/43312/Presentation_CIOPPIB.pdf.

24. Theorell T, Oxenstierna G, Westerlund H, Ferrie J, Hagberg J, Alfredsson L. Downsizing of staff is associated with lowered medically certified sick leave in female employees. J Occup Environ Med. 2003;60(9), http://dx.doi. org/10.1037/e334772004-001.

25. Westerlund H, Ferrie J, Hagberg J, Jeding K, Oxenstierna G, Theorell T. Workplace expansion, long-term sickness absence, and hospital admission. Lancet. 2004;9416(363): 1193-7, http://dx.doi.org/10.1016/s0140-6736(04)15949-7.

26. Kompass.com.pl. Warszawa: Kompass Poland Sp. z o.o. [cited 2014 Feb 20]. Available from: http://www.kompass. com.pl. Polish.

27. Pahkin K, Leppänen A, Kajosaari K, Ala-Laurinaho A, Welling I, Väänänen A, et at. [Developing well-being and 
managing sickness absences in the paper industry]. Helsinki: Työympäristötutkimuksen raporttisarja 48, Työterveyslaitos; 2010. Finnish.

28. Tvedt S, Saksvik P, Nytrø K. Does change process healthiness reduce the negative effects of organizational change on the psychosocial work environment? Work Stress. 2009;23:80-98.

29. Oreg S. Personality, context, and resistance to organizational change. Eur J Work Organ Psychol. 2006;15(1):73-101, http://dx.doi.org/10.1080/13594320500451247.

30. Karasek R, Theorell T. Healthy work: Stress, productivity, and the reconstruction of working life. New York: Basic Books; 1990.

31. Kristensen TS, Hannerz H, Høgh A, Borg V. The Copenhagen Psychosocial Questionnaire - A tool for the assessment and improvement of the psychosocial work environment. Scand J Work Environ Health. 2005;31:438-49, http://dx.doi.org/10.5271/sjweh.948.

32. Widerszal-Bazyl M, Radkiewicz P, Hasselhorn HM, Conway PM, van der Heijden B. The Demand-Control-Support model and intent to leave across 6 European countries: The role of employment opportunities. Work Stress. 2008;22(2):166-84.

33. Leineweber C, Wege N, Westerlund H, Theorell T, Wahrendorf M, Siegrist J. How valid is a short measure of effortreward imbalance at work? A replication study from Sweden. Occup Environ Med. 2010;67(8):526-31, http://dx.doi. org/10.1136/oem.2009.050930.

34. Kraan KO, Hooftman WE, de Jong T, Dhondt S. Cohort Study Social Innovation 2008-2010: Methodology and description of second wave. Hoofddorp: TNO; 2009.

35. Elo A-L, Leppänen A, Lindström K, Roponen T. Occupational Stress Questionnaire: User's instructions. Helsinki: Finnish Institute of Occupational Health; 1992.

36. Schaufeli WB, van Dierendonck D. [UBOS: The Utrecht Burnout Scale, Test Manual]. Lisse: Swets and Zeitlinger; 2000. Dutch.

37. Bossche SNJ, van den Koppes LLJ, Granzier JJM, Vroome EMM, de Smulders PGW. Netherlands Working
Conditions Survey 2007: Methodology and overall results. Hoofddorp: Netherlands Organisation for Applied Scientific Research TNO; 2008.

38. Schaufeli WB, Bakker AB, Salanova M. The measurement of work engagement with a short questionnaire. Educ Psychol Meas. 2006;66(4):701-16, http://dx.doi.org/ 10.1177/0013164405282471.

39. Chirkowska-Smolak T. [Psychological model of work engagement]. Poznań: Wydawnictwo Naukowe UAM; 2012. Polish.

40. Kauppinen T, Hanhela R, Heikkilä P, Kasvio A, Lehtinen S, Lindström K, et al., editors. [Work and health in Finland in 2006]. Helsinki: Finnish Institute of Occupational; 2007. Finnish.

41. Väänänen A, Ahola K, Koskinen A, Pahkin K, Kouvonen A. Organisational merger and psychiatric morbidity: A prospective study in a changing work organization. J Epidemiol Community Health. 2011;65(8):682-7, http://dx.doi. org/10.1136/jech.2010.126482.

42. Tuomi K, Ilmarinen J, Jahkola A, Katajarinne L, Tulkki A. Work Ability Index. 2nd revised ed. Helsinki: Finnish Institute of Occupational Health; 1998.

43. Pokorski J. [Work ability index - The Polish adaptation]. Kraków: Jagiellonian University; 1998. Polish.

44. Lindström K, Dallner M, Elo A-L, Gamberale F, Knardahl S, Skogstad A, et al., editors. Review of psychological and social factors at work and suggestions for the General Nordic Questionnaire (QPSNordic). Copenhagen, Nortd: Nordic Council of Ministers; 1997.

45. Jansen JP, van den Bosh FAJ, Volberda HW. Exploratory innovation, exploitative innovation, and performance: Effects of organizational antecedents and environmental moderators. Manag Sci. 2006;52(11):1661-74, http://dx.doi. org/10.1287/mnsc.1060.0576.

46. Bedyńska S, Książek M. [Statistical guidance 3. Practical guide to regression models and structural equation modeling]. Warszawa: Wydawnictwo Akademickie Sedno; 2012. Polish. 
47. Vahtera J, Virtanen M. The health effects of major organisational changes. Occup Environ Med. 2013;70(10):677-8, http://dx.doi.org/10.1136/oemed-2013-101635.

48. Hammond MH, Neff NL, Farr JL, Schwall AR, Zhao X. Predictors of individual-level innovation at work: A metaanalysis. Psychol Aesth Creat Arts. 2011;5(1):90-105, http:// dx.doi.org/10.1037/a0018556.

49. Kieselbach T, Armgarth E, Bagnara S, Elo E-L, Jefferys $\mathrm{S}$, Joling $\mathrm{C}$, et al. Health in restructuring: Innovative approaches and policy recommendations. München-Mering: Hampp; 2009.

50. Ruuskanen J, Kallio L, Salovaara-Simola R, Kaipainen J. Closing of the Voikkaa paper factory: Supporting the health of employees. In: Kieselbach T, Armgarth E, Bagnara S, Elo E-L, Jefferys S, Joling C, et al., editors. Health in restructuring. Innovative approaches and policy recommendations. München-Mering: Hampp; 2009.

This work is available in Open Access model and licensed under a Creative Commons Attribution-NonCommercial 3.0 Poland License - http://creativecommons.org/ licenses/by-nc/3.0/pl/deed.en. 